\title{
Psychological intervention improves life quality of patients with laryngeal cancer
}

\author{
This article was published in the following Dove Press journal: \\ Patient Preference and Adherence \\ 5 October 2017 \\ Number of times this article has been viewed
}

\author{
Xiaoli $\mathrm{Li}^{\prime}$ \\ Jingjing $\mathrm{Li}^{2}$ \\ Yanxia Shi ${ }^{2}$ \\ Ting Wang ${ }^{2}$ \\ Aling Zhang ${ }^{2}$ \\ $\mathrm{Na} \mathrm{Shao}{ }^{2}$ \\ Zhenghui Wang ${ }^{2}$ \\ 'Department of Dermatology, \\ ${ }^{2}$ Department of Otolaryngology- \\ Head and Neck Surgery, \\ The Second Affiliated Hospital, \\ Xi'an Jiaotong University, \\ Xi'an, People's Republic of China
}

Correspondence: Zhenghui Wang Department of Otolaryngology-Head and Neck Surgery, The Second Affiliated Hospital, Xi'an Jiaotong University, I57 Xi Wu Road, Xi'an, Shaanxi Province 71 0004, People's Republic of China

Tel +862987679866

Fax +86 2987678421

Email ehui4298@I63.com
Background: The purpose of this study is to examine the effect of psychological intervention on the life quality of patients with laryngeal cancer.

Methods: Two hundred and ten patients with laryngeal cancer were randomly assigned to the study group receiving psychological intervention and control group receiving routine nursing care. The Hamilton Depression Scale (HAMD), Hamilton Anxiety Scale (HAMA), and the Europe Organization for Research and Treatment of Cancer Quality of Life Questionnaire (EORTC QLQ-C30) were used to evaluate life quality.

Results: There were no significant differences in the scores of HAMD, HAMA, and EORTC QLQ-C30 between the 2 groups before treatment $(P>0.05)$. After treatment, the scores in the study group were significantly different to those in the control group $(P<0.05)$. In addition, the satisfaction rate and compliance rate of patients in the study group were increased, compared to the control group $(P<0.05)$.

Conclusion: Psychological intervention is beneficial in improving life quality in patients with laryngeal cancer after surgery.

Keywords: psychological intervention, compliance, laryngeal cancer

\section{Introduction}

Laryngeal cancer is one of the most frequently diagnosed malignancies in head and neck, accounting for $5.7 \%-7.6 \%$ of all cancer cases. ${ }^{1}$ Environmental pollution, especially in some developing countries, is an important contributor to the increasing incidence of laryngeal cancer. ${ }^{2}$ Common symptoms include hoarseness, dysphagia, trouble breathing, and lump in the neck. ${ }^{3}$ Surgery is currently the main treatment for laryngeal cancer. ${ }^{4}$ The 5-year survival rate for patients with laryngeal cancer at stages I and II is $>68 \%$ after surgical resection, while at stages III and IV the survival rate is only $40 \%-50 \%$. Laryngectomy, either partial or total, is associated with a high incidence of postoperative complications, thus reducing life quality and leading to poor compliance. ${ }^{5-7}$

In the present study, we implemented psychological intervention nursing in patients with laryngeal cancer during hospitalization. The Hamilton Depression Scale (HAMD), Hamilton Anxiety Scale (HAMA), Europe Organization for Research and Treatment of Cancer Quality of Life Questionnaire (EORTC QLQ-C30), satisfaction rate, and adherence rate were used to assess the effect of psychological intervention.

\section{Patients and methods}

\section{Patients}

We enrolled 210 patients with laryngeal cancer who were admitted to the Department of Otolaryngology-Head and Neck Surgery of The Second Affiliated Hospital of Xi'an Jiaotong University (Xi'an, People’s Republic of China) from March 2014 to 
August 2016. Written informed consent for research was obtained from each patient, and this study was approved by the Institutional Human Experiment and Ethics Committee of The Second Affiliated Hospital of Xi'an Jiaotong University. Inclusion criteria were pathological diagnosis of laryngeal cancer, eligibility to receive psychological intervention, and normal psychological behaviors. The patients were randomly assigned to 2 groups: control group $(n=108)$ and intervention group $(n=102)$. In the control group, there were 62 males and 46 females, with a mean age of 55.25 \pm 2.38 years (range, 39-76 years). In the intervention group, 59 were men and 43 were women, with a mean age of 55.27 \pm 2.40 years (range, $40-76$ years). Concerning their education, 42 and 38 patients graduated from high school and 47 and 44 patients had a bachelor's degree in the control and intervention groups, respectively. No significant difference in the parameters studied was noted between the 2 groups. Patients in the intervention group were given psychological intervention, while those in the control group were given a standard nursing care (Figure 1).

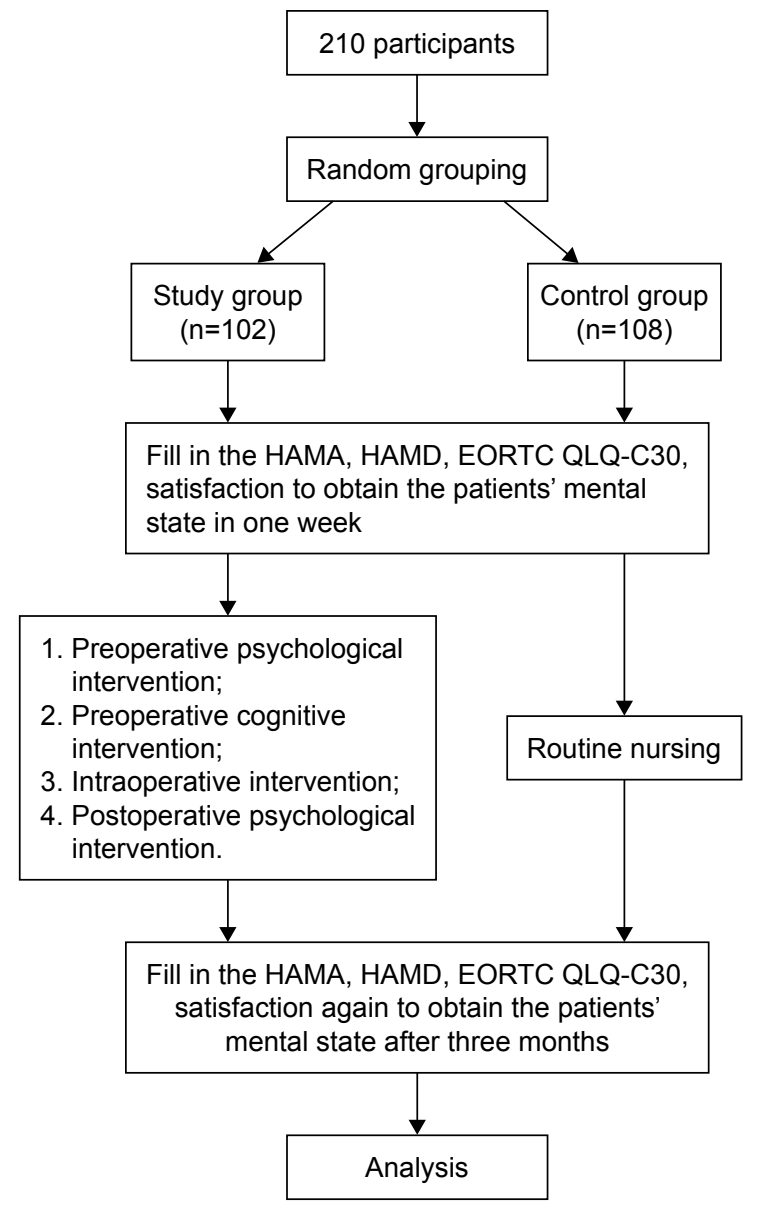

Figure I Outline of study design.

Abbreviations: HAMA, Hamilton Anxiety Scale; HAMD, Hamilton Depression Scale; EORTC QLQ-C30, Europe Organization for Research and Treatment of Cancer Quality of Life Questionnaire.

\section{Psychological intervention}

We developed a series of patient intervention programs. The detailed protocols are summarized in this paper. Before surgery, clinicians explained advanced surgical instruments and procedures to patients and encouraged them to receive the therapy. Also, patients were informed of the potential surgery-related risks and complications. Preoperative psychological intervention aimed to reduce anxiety levels of patients. ${ }^{8}$ Moreover, description of successful surgical cases will enhance the confidence of the patients. Patients were warmly welcomed to the operating room. Nurses should provide a continuity of care throughout the perioperative period and explain to the patients what will happen during operation, attempting to alleviate any anxieties from surgery. After operation, the majority of patients find it difficult to accept the fact that they have lost the ability to speak. Therefore, it is important for nurses to provide delicate care and encourage them to face reality. In addition, patients need to be taught how to clean and sterilize the inner cannula, which would help them to increase self-care capacity.

\section{Control group}

The control group received routine nursing care, including introduction to the equipment and the environment. Patients were instructed to communicate through body language, pay attention to clean the oral cavity, and stop drinking and smoking. Meanwhile, nurses informed them regarding the operation necessity and attention after operation.

\section{Observations}

HAMA, HAMD, and EORTC QLQ-C30 assessment was performed by 8 nurses at 1 week before and 3 months after surgery. Mean durations and costs of hospitalization were recorded. Degree of satisfaction of patients was scored using Likert scales, ranging 1-5 (1= very unsatisfactory; $2=$ unsatisfactory; $3=$ moderate; $4=$ satisfactory; $5=$ very satisfactory). The questionnaire consisted of 10 single choice questions and 10 multiple choice questions. The scoring ranged from 1 to 5 points per question $(1=$ much worse; $2=$ worse; $3=$ good; $4=$ better; $5=$ much better). The maximum score was 100 .

\section{Statistical analysis}

Data analysis was performed using SPSS software (version 17.0; SPSS Inc., Chicago, IL, USA). A Student's $t$-test and chi-square test were used to compare HAMA, HAMD, and EORTC QLQ-C30 between the 2 groups before and after treatment. Statistical significance was set at $P<0.05$. 
Table I Comparison of HAMD and HAMA scores between the 2 groups

\begin{tabular}{|c|c|c|c|c|c|c|c|c|c|}
\hline \multirow[t]{2}{*}{ Group } & \multirow{2}{*}{$\begin{array}{l}\text { Number } \\
\text { of patients }\end{array}$} & \multicolumn{2}{|c|}{ HAMD score } & \multirow[t]{2}{*}{$t$} & \multirow[t]{2}{*}{$P$-value } & \multicolumn{2}{|c|}{ HAMA score } & \multirow[t]{2}{*}{$t$} & \multirow[t]{2}{*}{$P$-value } \\
\hline & & $\begin{array}{l}\text { Before } \\
\text { treatment }\end{array}$ & $\begin{array}{l}\text { After } \\
\text { treatment }\end{array}$ & & & $\begin{array}{l}\text { Before } \\
\text { treatment }\end{array}$ & $\begin{array}{l}\text { After } \\
\text { treatment }\end{array}$ & & \\
\hline Study group & 102 & $24.7 \pm 2.5$ & $15.4 \pm 1.7$ & 10.55 & 0.00 & $32.5 \pm 5.6$ & $7.9 \pm 1.1$ & 9.77 & 0.00 \\
\hline Control group & 108 & $24.2 \pm 2.5$ & $19.4 \pm 2.8$ & 4.34 & 0.00 & $32.64 \pm 5.3$ & $|4.1 \pm 2| .7$ & 4.52 & 0.00 \\
\hline Statistical value & & 0.67 & 17.99 & & & 0.67 & 18.56 & & \\
\hline$P$ & & 0.71 & 0.00 & & & 0.23 & 0.00 & & \\
\hline
\end{tabular}

Note: Data shown as mean \pm standard deviation.

Abbreviations: HAMD, Hamilton Depression Scale; HAMA, Hamilton Anxiety Scale.

\section{Results}

\section{HAMD and HAMA scores}

The HAMD and HAMA scores were significantly reduced in both the groups after treatment $(P<0.05$ vs. control values before treatment; Table 1). Moreover, compared to the control group, the intervention group had significantly lower HAMD and HAMA scores $(P<0.05)$, suggesting a reduction of anxiety levels.

\section{Assessment of survival quality}

In terms of physical health, mental health, social function, self-evaluation, and special adverse reaction, patients in the intervention group had a significant improvement after treatment ( $P<0.05$ vs the scores before treatment; Table 2$)$. By contrast, patients in the control group had only an improvement of physical health after treatment.

\section{Hospitalization duration and expenses, and patient satisfaction}

With regard to hospitalization duration and expenses, there were significant differences between the 2 groups $(P<0.05$; Table 3$)$. In addition, the 2 groups differed significantly in the satisfaction rate and compliance rate $(P<0.05$; Table 3$)$.

\section{Discussion}

Quality of life is a multi-dimensional concept and quantitative measure that reflects physical activity and psychological status, which are associated with happiness, satisfaction, or gratification. ${ }^{9}$

With the change of modern medical model from biomedical model to biopsychosocial medical model, psychology has been widely used in clinic. ${ }^{10}$ Traditional medical therapies focus on the resolution of physical symptoms and prolongation of life span, but spare psychological disorders. Therefore, the purpose of improving the quality of treatment should include improvement of the quality of life of patients, restoration of the patient's physical function, and maintenance of healthy psychological state of patients and social function.

Cancer-related emotional disorder has a deleterious impact on quality of life and patient compliance, consequently reducing overall survival by $10 \%-20 \%{ }^{11,12}$ After surgery, patients experience a painful process, such as pain, dry mouth, sticky saliva, feeling ill, and use of painkillers. They can easily suffer from depression and anxiety and commit suicide. Psychological intervention can preserve the confidence of patients, improve quality of life, and reduce cancer-specific anxiety and stress. For patients with laryngeal cancer, psychological intervention is particularly necessary because of the dramatic physical changes after surgery, such as loss of phonation, hyposmia, hypogeusia, and frequent coughing. ${ }^{13,14}$ This study was conducted to explore the clinical significance of psychological intervention in patients with laryngeal cancer. We found that HAMA and

Table 2 Comparison of QOL score and each dimension between the 2 groups

\begin{tabular}{|c|c|c|c|c|}
\hline & \multicolumn{2}{|c|}{ Study group $(n=102)$} & \multicolumn{2}{|c|}{ Control group $(n=108)$} \\
\hline & $\begin{array}{l}\text { Before } \\
\text { treatment }\end{array}$ & $\begin{array}{l}\text { After } \\
\text { treatment }\end{array}$ & $\begin{array}{l}\text { Before } \\
\text { treatment }\end{array}$ & $\begin{array}{l}\text { After } \\
\text { treatment }\end{array}$ \\
\hline General physical health & $11.54 \pm 2.16 * *$ & $15.65 \pm 2.24 * *$ & $13.06 \pm 3.23 *$ & $14.35 \pm 2.54 *$ \\
\hline Mental state & $15.26 \pm 4.75^{* *}$ & $21.16 \pm 4.12^{* *}$ & $17.14 \pm 4.56$ & $18.76 \pm 4.98$ \\
\hline Function of society and family & $13.58 \pm 2.23 *$ & $15.45 \pm 2.67 *$ & $|3.67 \pm 2.2|$ & $14.52 \pm 3.28$ \\
\hline Symptoms and side effects & $|0.87 \pm 2.0| *$ & $16.47 \pm 1.89 *$ & $10.38 \pm 2.62$ & $11.87 \pm 2.34$ \\
\hline Self-evaluated quality of life & $5.32 \pm 1.01 *$ & $7.39 \pm 1.42 *$ & $5.28 \pm 1.04$ & $6.43 \pm 2.01$ \\
\hline Special side effects & $7.00 \pm 2.43 * *$ & $4.07 \pm 4.65 * *$ & $6.46 \pm 4.26$ & $8.02 \pm 2.49$ \\
\hline Total score & $56.32 \pm 7.8^{*}$ & $76.58 \pm 9.6^{*}$ & $62.38 \pm 11.46$ & $64.28 \pm 12.49$ \\
\hline
\end{tabular}

Notes: $* P<0.05, * * P<0.01$. Data shown as mean \pm standard deviation.

Abbreviation: QOL, quality of life. 
Table 3 Comparison of hospitalization duration, hospitalization expenses, patient satisfaction, and compliance rate between the 2 groups

\begin{tabular}{lllll}
\hline Group & $\begin{array}{l}\text { Number } \\
\text { of patients }\end{array}$ & $\begin{array}{l}\text { Average duration } \\
\text { hospitalization (D) }\end{array}$ & $\begin{array}{l}\text { Average hospitalization } \\
\text { expenses (RMB) }\end{array}$ & $\begin{array}{l}\text { Satisfaction } \\
\text { (\%) }\end{array}$ \\
\hline Study group & 102 & $17.65 \pm 2.85^{*}$ & $15,109 \pm 1,453.34 *$ & $95.41 \pm 2.24 * *$ \\
Control group & 108 & $21.31 \pm 4.82 *$ & $19,024 \pm 2,457.26 *$ & $92.33 \pm 4.29 *$ \\
\hline
\end{tabular}

Notes: $* P<0.05, * * P<0.01$. Data shown as mean \pm standard deviation.

HAMD scores were significantly reduced in the intervention group, compared to the control group. Moreover, the life quality of patients in the intervention group improved after treatment. These data suggest that psychological intervention can alleviate anxiety levels and thus provide survival benefits to cancer patients.

Our data also showed that hospitalization duration and expense reduced and patient satisfaction increased in the intervention group, compared to the control group. These results suggest that psychological intervention contributes to the recovery of wounds after surgery. The reduction in therapy expense may enhance patient compliance. Increasing evidence indicates the importance of psychological intervention in the treatment of cancer patients. However, psychological intervention of cancer patients has not been widely employed in local hospitals in the People's Republic of China.

With the rapid development of medical psychology in recent years, psychological intervention for improving the negative emotion of cancer patients, therapeutic effect, patient compliance, and quality of life of patients has attracted the attention of the whole society; some studies have proved that psychological intervention has become an integral part of the overall treatment of tumor. ${ }^{15}$ Although psychological intervention plays an important role in the treatment of tumors, the psychological intervention has not been widely used in the People's Republic of China, especially in primary hospitals, even without a psychotherapist. ${ }^{16}$ The results of this study found that psychological intervention could improve anxiety, depression, and quality of life of patients. Therefore, in addition to the necessary surgery and drug treatment, psychological intervention is worthy of popularization and application.

\section{Conclusion}

Our data support that psychological intervention can improve the life quality of patients with laryngeal cancer. The psychological intervention should not be underestimated in clinical research.

\section{Acknowledgment}

This work was supported by funds from The Second Affiliated Hospital of Xi' an Jiaotong University and Shaan'xi Province Government (2015SF169).

\section{Disclosure}

The authors report no conflicts of interest in this work.

\section{References}

1. García Lorenzo J, Montoro Martínez V, Rigo Quera A, et al. Modifications in the treatment of advanced laryngeal cancer throughout the last 30 years. Eur Arch Otorhinolaryngol. Epub 2017 Jun 17. doi:10.1007/ s00405-017-4639-z.

2. Nachalon Y, Cohen O, Alkan U, Shvero J, Popovtzer A. Characteristics and outcome of laryngeal squamous cell carcinoma in young adults. Oncol Lett. 2017;13(3):1393-1397.

3. Zahoor T, Dawson R, Sen M, Makura Z. Transoral laser resection or radiotherapy? Patient choice in the treatment of early laryngeal cancer: a prospective observational cohort study. J Laryngol Otol. 2017; 131(6):541-545.

4. García-León FJ, García-Estepa R, Romero-Tabares A, Gómez-Millán Borrachina J. Treatment of advanced laryngeal cancer and quality of life. Acta Otorrinolaringol Esp. 2017;68(4):212-219. Spanish [with English abstract].

5. Bhanu Prasad V, Mallick S, Upadhyay AD, Rath GK. Systematic review and individual patient data analysis of pediatric head and neck squamous cell carcinoma: an analysis of 217 cases. Int J Pediatr Otorhinolaryngol. 2017;92:75-81.

6. Rzepakowska A, Sielska-Badurek E, Osuch-Wójcikiewicz E, Niemczyk K. Multiparametric assessment of voice quality and quality of life in patients undergoing microlaryngeal surgery-correlation between subjective and objective methods. J Voice. Epub 2017 May 23. pii: S08921997(17)30034-6.

7. Costa JM, López M, García J, León X, Quer M. Impact of total laryngectomy on return to work. Acta Otorrinolaringol Esp. Epub 2017 May 17. pii: S0001-6519(17)30089-4. Spanish [with English abstract].

8. Sun X, Yang H, Shao DM, Zheng Y. Application and effect assessment of comfort care model in laryngeal neoplasms patients after total laryngectomy. Chin Nurs Manag. 2009;9(8):69-71. Chinese [with English abstract].

9. Baker CA. Factors associated with rehabilitation in head and neck cancer. Cancer Nurs. 1992;15(6):395-400.

10. Gelder M, Gath D, Mayou R. Oxford Textbook of Psychiatry. Oxford; New York: Oxford University Press; 1983:152,296,350-351.

11. Kardasz-Ziomek M, Scierski W, Namysowski G, Majewski W. [Long-term results of partial laryngectomies in patients suffering from laryngeal cancer]. Otolaryngol Pol. 2012;66(1):46-50. Polish [with English abstract].

12. Trzcieniecka-Green A, Bargiel-Matusiewicz K, Borczyk J. Quality of life of patients after laryngectomy. J Physiol Pharmacol. 2007;58 Suppl 5(Pt 2):699-704. 
13. Kardasz-Ziomek M, Ścierski W, Namysłowski G. [Operation treatment results of laryngeal cancer in different types of partial laryngectomy based on own material]. Otolaryngol Pol. 2014;68(5):233-238. Polish [with English abstract].

14. Serra A, Di Mauro P, Spataro D, Maiolino L, Cocuzza S. Postlaryngectomy voice rehabilitation with voice prosthesis: 15 years experience of the ENT Clinic of University of Catania. Retrospective data analysis and literature review. Acta Otorhinolaryngol Ital. 2015;35(6):412-419. Italian [with English abstract].
15. Lee YH, Lai YH, Yueh B, et al. Validation of the University of Washington Quality of Life Chinese Version (UWQOL-C) for head and neck cancer patients in Taiwan. J Formos Med Assoc. 2017;116(4): 249-256.

16. Liu D, Zhang XY, Guo QY, Zhu QQ. Evaluation and analysis of quality of life in patients following laryngectomy. Chin J Ophthalmol Otorhinolaryngol. 2010;10(4):232-235.

\section{Publish your work in this journal}

Patient Preference and Adherence is an international, peer-reviewed, open access journal that focuses on the growing importance of patient preference and adherence throughout the therapeutic continuum. Patient satisfaction, acceptability, quality of life, compliance, persistence and their role in developing new therapeutic modalities and compounds to optimize clinical outcomes for existing disease states are major areas of interest for the journal. This journal has been accepted for indexing on PubMed Central. The manuscript management system is completely online and includes a very quick and fair peer-review system, which is all easy to use. Visit http://www. dovepress.com/testimonials.php to read real quotes from published authors.

\footnotetext{
Submit your manuscript here: http://www.dovepress.com/patient-preference-and-adherence-journal
} 